\title{
Avaliação sorológica do vírus da doença de Newcastle em aves silvestres
}

\section{Serological survey of Newcastle disease virus in wild birds}

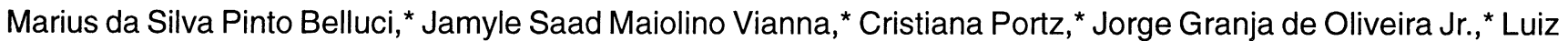 \\ Paulo Luzes Fedullo, ${ }^{*}$ Carlos Mazur, ${ }^{*}$ Cláudio de Moraes Andrade*
}

\begin{abstract}
Resumo
O vírus da doença de Newcastle (VDN) tem sido isolado na maioria das espécies de aves em todo mundo. Infecções naturais e experimentais já foram demonstradas em pelo menos 236 espécies de aves (Kaleta \& Baldauf, 1988). O comércio internacional de aves também deve ser considerado como um fator importante de disseminação da doença. $\mathrm{Na}$ avicultura industrial, o VDN pode causar uma grande mortalidade e perdas econômicas. Portanto, aves silvestres, livres ou cativas, podem atuar como reservatório para o VDN. Para analisar esta hipótese, aves da Fundação RioZoo e de outras propriedades particulares foram sangradas e seus plasmas estocados com vista à realização de uma pesquisa sorológica para detecção de níveis significativos de anticorpos para VDN. Um painel de 253 plasmas foi obtido e analisado pelo teste de inibição da hemaglutinação $(\mathrm{HI})$. Os oito plasmas positivos para VDN foram tratados com 2mercaptoetanol e novamente testados por $\mathrm{HI}$, com o objetivo de eliminar anticorpos do isotipo M (IgM), preservando apenas os níveis de IgY (a classe IgY nas aves corresponde à IgG, em mamíferos). A presença significativa de IgM detectada em alguns plasmas sugeriu a exposição recente das aves estudadas ao VDN.
\end{abstract}

Palavras-chave: Doença de Newcastle; paramyxovirus; aves.

\section{Introdução}

A Doença de Newcastle é causada por um vírus RNA da família Paramyxoviridae, gênero Rubulavirus. Seus virions são envelopados e apresentam o nucleocapsídeo com simetria helicoidal. A virulência e patogenicidade das amostras virais de campo são altamente variáveis. Nos casos em que se observam infecções brandas ou inaparentes do trato respiratório, a apresentação da doença é denominada lentogênica. Quando o desenvolvimento da doença leva à mortalidade de até $25 \%$ do plantel, principalmente de aves jovens, a forma da doença é denominada mesogênica. Por último, podem ocorrer taxas de mortalidade muito elevadas, em torno de $100 \%$. Estes casos, marcados por infecções agudas e letais em aves de todas as idades, com lesões hemorrágicas no trato digestivo ou com sinais neurológicos graves, correspondem à forma velogênica da doença. As perdas econômicas derivam da alta mortalidade associada às formas mesogênicas e velogênicas, assim como à diminuição do ganho de peso e decréscimo na produção de aves afetadas pela forma lentogênica da doença (Alexander, 1997). Com a modernização da avicultura industrial, incrementada principalmente pelas inovações tecnológicas, o Brasil tornou-se um dos maiores produtores do mercado internacional (Wright, 1994). A importância econômica e social da avicultura brasileira levou o Ministério da Agricultura a instituir o Programa Nacional de Sanidade Avícola (PNSA) para possibilitar a aceitação dos produtos nacionais nos mercados mundiais. OPNSA contemplou o VDN como um dos principais patógenos da avicultura industrial, normatizando as rotinas de diagnóstico laboratorial (Brasil - MAARA, 1994).

No Estado do Rio de Janeiro, as aves ornamentais e silvestres mantidas em cativeiro - as aves vacinadas, criadas para consumo próprio, e as de vida livre - são muito importantes sob o ponto de vista epidemiológico, pois podem representar reservatórios para o VDN. Com o objetivo de analisar esta hipótese, aves do Zoológico do Rio de Janeiro (Fundação RioZoo), de outras localidades próximas ou mesmo de cidades vizinhas foram sangradas e seus plasmas analisados sorologicamente para detecção de níveis significativos de anticorpos específicos para VDN.

\section{Material e métodos}

\section{Coleta e processamento dos plasmas}

Foram coletadas amostras de sangue de 253 aves, por punção da veia braquial com seringas heparinizadas. Entre as aves coletadas, 170 pertenciam à Fundação RioZoo e as restantes estavam distribuídas em pequenas propriedades na área de influência da UFRRJ (Rio de Janeiro e cidades vizinhas). Os plasmas foram obtidos por centrifugação a 600 gravidades por 10 minutos, em temperatura ambiente, inativados a $56^{\circ} \mathrm{C}$, por 30 minutos. Para remoção de

\footnotetext{
* Fundação RioZoo - Rio de Janeiro, RJ.
} 
hemaglutininas inespecíficas, adicionou-se uma suspensão de hemácias de galinha a $50 \%$, no volume correspondente a $10 \%$ do volume de cada plasma. Após 60 minutos, os plasmas foram novamente separados por centrifugação a 600 gravidades, por 10 minutos, em temperatura ambiente e estocados a $-20^{\circ} \mathrm{C}$, até o momento do uso (Brasil - MAARA, 1994).

\section{Teste de inibição da hemaglutinação (HI)}

Para pesquisa de anticorpos, o teste $(\mathrm{HI})$ foi realizado por microtécnica em placas de 96 cavidades com fundo em " $U$ ". A capacidade hemaglutinante do antígeno viral, que foi utilizado no teste de $\mathrm{HI}$, foi titulada pelo teste de hemaglutinação (HA). Para o teste de HI, 25 microlitros de cada plasma coletado foram diluídos na base logarítmica 2, em tampão fosfato, $\mathrm{pH}$ 7,2 (PBS), e o mesmo volume do antígeno viral a 4 UHA foi adicionado a cada diluição. As diluições dos plasmas com antígeno viral foram incubadas a aproximadamente $25^{\circ} \mathrm{C}$ (temperatura ambiente). Em seguida, 25 microlitros de uma suspensão de hemácias de galinha, a 1\% em tampão fosfato (PBS), foi acrescentada a cada mistura de plasma e antígeno. As microplacas com as diluições dos plasmas incubados com antígeno viral e hemácias de galinha foram mantidas por mais 30 minutos, em temperatura ambiente. $O$ título de anticorpos dos plasmas foi definido como o inverso da maior diluição de plasma capaz de inibir completamente a atividade hemaglutinante. Títulos iguais ou maiores que oito foram considerados positivos (Brasil - MAARA. 1994). Soro hiperimune para VDN e plasmas foram empregados nos testes de $\mathrm{HI}$, como controle positivo e negativo, respecti- vamente. Para doação de plasma negativo e hemácias, aves doadoras, provenientes de ovos embrionados SPF (Specific Pathogen Free), foram criadas e mantidas em isolamento nas instalações do Laboratório de Viroses Veterinárias, do Departamento de Epidemiologia e Saúde Pública da UFRRJ. O soro hiperimune e o antígeno viral (VDN inativado, amostra Ulster) utilizados como controles foram cedidos pelo Laboratório de Referência Animal (LARA) de Campinas - SP, do Ministério da Agricultura.

\section{Tratamento com 2-mercaptoetanol}

Os plasmas positivos foram tratados com 2-mercaptoetanol e novamente testados por $\mathrm{HI}$, para análise da presença de IgM. Para esta finalidade, adicionou-se a 25 microlitros dos plasmas positivos igual volume de uma solução de $0,1 \mathrm{M}$ de 2-mercaptoetanol em PBS, e deixou-se a mistura a $37^{\circ} \mathrm{C}$, por 60 minutos. Uma redução igual ou maior que 4 vezes no título de anticorpos, após o tratamento com 2-mercaptoetanol indicou a presença significativa de IgM (Bricout et al., 1974).

\section{Resultados e discussão}

Do painel de 253 plasmas coletados e testados por $\mathrm{HI}$, oito aves soropositivas foram detectadas, todas pertencentes à Fundação RioZoo, correspondendo a 3,2\% do total. Entretanto, quando observadas apenas as aves coletadas na Fundação RioZoo (170), 4,7\% destas apresentaram níveis significativos de anticorpos para VDN. Dos oito plasmas tratados com mercaptoetanol, três apresentaram uma queda significativa dos títulos, sugerindo uma exposição recente ao VDN (Tabela 1).

Tabela 1: Resultados da avaliação sorológica

\begin{tabular}{|c|c|c|c|c|c|}
\hline \multicolumn{3}{|c|}{ IDENTIFICAÇÃO DAS AVES } & \multicolumn{3}{|c|}{ TÍTULOS DOS PLASMAS POSITIVOS* } \\
\hline $\mathrm{N}^{0}$ & NOME VULGAR & NOME CIENTÍFICO & Inicial & $\begin{array}{l}\text { Tratamento com } \\
\text { mercaptoetanol }\end{array}$ & . Presença de IgM \\
\hline 56 & Faisão Dourado & Chysolophus pictus & 16 & 4 & + \\
\hline 70 & Faisão Prateado & Lophura leucomelana & 16 & 4 & + \\
\hline 93 & Carcará & Polyborus plancus & 64 & 32 & - \\
\hline 94 & Urubutinga & Buteogallus urubutinga & 8 & 4 & - \\
\hline 95 & Carcará & Polyborus plancus & 8 & 8 & - \\
\hline 117 & Conuja Buraqueira & Athene cunicularia & 8 & 4 & - \\
\hline 129 & Caracará & Polyborus plancus & 16 & 16 & - \\
\hline 138 & Faisão Prateado & Lophura leucomelana & 128 & 32 & + \\
\hline
\end{tabular}

*Os títulos estão apresentados como o inverso da maior diluição em que ocorreu a inibição completa da hemaglutinação, na prova de HI.

A tabela apresenta o resultado da avaliação sorológica por $\mathrm{HI}$, nos plasmas das aves silvestres, antes (título inicial) e depois do tratamento com mercaptoetanol.

O VDN é considerado um dos patógenos mais importantes na avicultura industrial brasileira e amostras lentogêni- nicas como a Hitchner B1, La Sota ou Ulster têm sido largamente empregadas como vacinas no controle da Doença de Newcastle. A vacinação de aves em todo o mundo também dificulta o estudo da distribuição geográfica do VDN (Alexander, 1997). Três panzootias ocorreram, des- 
de a primeira identificação da doença em 1926 (Alexander, 1988). O primeiro relato da Doença de Newcastle no Brasil coincide com a ocorrência da primeira panzootia estudada, no final dos anos 40 (Hastenreiter, 1976). A segunda panzootia originou-se na América do Sul, a partir de aves silvestres, na década de 70 (Walker et al., 1972). Atualmente, as aves oriundas de florestas tropicais são consideradas os principais reservatórios do VDN (Cross, 1996).

Parte da complexidade do problema pode ser compreendida a partir da mutagenicidade do genoma de RNA dos paramyxovirus que, eventualmente, viabilizou o surgimento da grande variabilidade entre as amostras virais do VDN, incluindo as velogênicas. Mesmo amostras lentogênicas têm importância para a produção comercial por estarem associadas à queda de produção de ovos e ganho de peso. Esta mutagenicidade, juntamente com a grande gama de hospedeiros, torna o surgimento de novas amostras patogênicas, um risco em potencial. Portanto, uma política de vigilância sanitária baseada em levantamentos sorológicos e no estabelecimento do diagnóstico de rotina deve ser continuamente renovada. Como é possível que todas as espécies de aves sejam susceptíveis à infecção, o trânsito internacional destas deve ser observado cuidadosamente. Além do comércio interno e externo legalizado, aves silvestres são comercializadas ilicitamente, em grande escala, devido ao forte interesse econômico. A análise sorológica apresentada neste trabalho, com caráter de vigilância sanitária, representa um importante instrumento de estudo epidemiológico, sugerindo a circulação do VDN na população alvo estudada.

\section{Conclusão}

Os resultados da pesquisa sorológica, bem como a presença de níveis significativos de IgM em alguns plasmas, sugerem a circulação do VDN em aves silvestres, especialmente na Fundação RioZoo e reafirmam a importância destas, como reservatório para o VDN. Os resultados também indicam a importância de novas análises epidemiológicas e tentativas de isolamento de amostras virais para estudos em perspectiva sobre o VDN.

\begin{abstract}
Newcastle Disease Virus (NDV) has been isolated from most species of wild and domestic birds all over the world. Natural and experimental infections have been demonstrated in at least 236 species of birds (Kaleta \& Baldauf, 1988). The international trade of birds must be also considered an important factor on spreading of the disease and in industrial aviculture, NDV may cause great mortality and economical losses. Therefore, wild birds, caged or free either may act as a reservoir for NDV. To analyze this hypothesis, birds of the Rio de Janeiro Zoo (Fundação RioZoo) and other locations were bled and its plasms stored. A serological survey was done regarding to detect significant levels of specific antibodies against NDV. A panel of 253 plasmas were collected and tested by hemmaglutination inhibition assay $(\mathrm{HI})$. The eight positive plasmas were treated with 2-mercaptoethanol and tested again by $\mathrm{HI}$, in order to eliminate immunoglobulins of isotype $\mathrm{M}(\operatorname{lgM})$, only preserving IgY levels (the class IgY, in birds, corresponds to IgM, in mammalians). The significative presence of IgM found in some plasmas suggests the birds have been exposed to NDV recently.
\end{abstract}

Keywords: Newcastle Disease; paramyxovirus; birds.

\title{
Agradecimentos
}

Agradecimentos à Dra. Ma das Graças M. Danelli pelo auxílio na interpretação dos resultados das análises sorológicas. À Dra Maria Ângela Orsi e Dr.Luciano Doretto Jr, LARA-Campinas, pela doação de soro hiperminune e antígeno viral inativado. À FAPERJ, CNPq e CAPES pelo suporte financeiro.

\section{Referências bibliográficas}

ALEXANDER, D.J. Historical Aspects. In: D.J. Alexander (Ed.), Newcastle Disease, p. 1-10. Kluwer Academic Publ., Boston, 1988.

Newcastle disease and other paramyxovirus infections. In: Diseases of Poultry, $10^{\text {th }}$ ed. B.W.Calnek, H.J. Barnes, C.W. Beard, W.M. Reid \& H.W. Yoder, Jr., Ames, lowa. p. 496-519, 1997.

BRASIL .MAARA. Programa Nacional de Sanidade Avícola. Atos Legais, p. 83, 1994.

BRICOUT, F., JOUBERT, L., HURAUX, J.M. Techiniques de base diagnostic séreo immunologique de viroses humaines et animales; $6^{\mathrm{me}}$ ed., p.152, 1974.
CROSS, G. Avian Viral Diseases In: Diseases of Cage and Aviary Birds, 3rd edition, Rosskopf, W.J. \& Woerpel, R.W., Williams and Wilkins, Baltimore, Maryland, p. 548-567, 1996.

HASTENREITER, H. La Maladie de Newcastle au Brésil . Bull. Off. Int. Epiz. v. 85, n. 7-8, p. 813-817, 1976.

KALETA E.F., BALDAUF C. Newcastle Disease in free-living pet birds. In: Newcastle Disease. D.J. Alexander, Ed., Kluwer Academic Publishers, Boston, p. 197-246, 1988.

WALKER JW. HERON, B.R., MIXSON, M.A. Exotic Newcastle Disease erradication program in the United States. Avian Diseases, n. 16, p. 486-503, 1972.

WRIGHT C. Pollo a la Brasileña. Industria Avicola v. 41, n. 12, p. 20-30, 1994. 